\title{
Personal tumor antigens in blood malignancies: genomics-directed identification and targeting
}

\author{
Livius Penter ${ }^{1,2}$ and Catherine J. $\mathrm{Wu}^{2,3,4,5}$ \\ 'Department of Hematology, Oncology, and Tumor Immunology, Charité - Universitätsmedizin Berlin (CVK), Berlin, Germany. ${ }^{2}$ Department of Medical Oncology, Dana-Farber Cancer Institute, Boston, \\ Massachusetts, USA. ${ }^{3}$ Broad Institute, Massachusetts Institute of Technology and Harvard University, Cambridge, Massachusetts, USA. ${ }^{4}$ Harvard Medical School, Boston, Massachusetts, USA. ${ }^{5}$ Department \\ of Medicine, Brigham and Women's Hospital, Boston, Massachusetts, USA.
}

\begin{abstract}
Hematological malignancies have long been at the forefront of the development of novel immune-based treatment strategies. The earliest successful efforts originated from the extensive body of work in the field of allogeneic hematopoietic stem cell transplantation. These efforts laid the foundation for the recent exciting era of cancer immunotherapy, which includes immune checkpoint blockade, personal neoantigen vaccines, and adoptive T cell transfer. At the heart of the specificity of these novel strategies is the recognition of target antigens presented by malignant cells to $\mathrm{T}$ cells. Here, we review the advances in systematic identification of minor histocompatibility antigens and neoantigens arising from personal somatic alterations or recurrent driver mutations. These exciting efforts pave the path for the implementation of personalized combinatorial cancer therapy.
\end{abstract}

In recent years, the clinical successes of immune checkpoint blockade (ICB) have ignited broad enthusiasm for understanding and utilizing the modulation of immune control in order to meaningfully induce cancer control across diverse solid tumors and blood malignancies (1-6). Investigations into the basis of these dramatic immune responses have yielded numerous insights, including the critical contributions of infiltrating $\mathrm{T}$ lymphocytes within the tumor microenvironment and the control and expression of negative immunoregulatory checkpoints in tumors and within their milieu (7-9).

Another key insight from these investigations has been the observation of tumor neoantigens as critical targets driving the effective $\mathrm{T}$ cell responses associated with these novel therapies (10, 11). The identification of tumor-specific antigens has always been a high priority, since this focuses efforts toward precise immunological targeting. Tumor neoantigens arising from mutations have long been considered potentially optimal tumor antigens given their exquisite tumor-restricted expression and their high level of immunogenicity due to the lack of central tolerance against them (12). However, until next-generation sequencing technologies became available over the past decade, there were considerable challenges to neoantigen identification on a patient-specific basis. The blood malignancies have been consistently at the forefront of targeted cellular therapy and combinatorial immune-based treatment approaches (13). Here, we review the experience of allogeneic hematopoietic stem cell transplantation (HSCT) for the curative treatment of blood malignancies, which has provided the field with the first evidence that the targeting of antigens aris-

Conflict of interest: CJW is a cofounder of Neon Therapeutics and is a member of its scientific advisory board.

Copyright: (5) 2020, American Society for Clinical Investigation.

Reference information: J Clin Invest. 2020;130(4):1595-1607.

https://doi.org/10.1172/JCl129209. ing from patient-specific DNA changes could give rise to clinically meaningful immunological responses (14). We describe the range of antigen candidates that have been identified across blood malignancies through genomic analyses and consider how these can be effectively therapeutically targeted using combinatorial approaches (Table 1).

\section{mHAs: early examples of genomically defined immune targets}

To a certain extent, the recent demonstrations of human immune responses against tumor neoantigens across diverse malignancies are not surprising, given the backdrop of long-standing studies in the field of HSCT for blood malignancies (15). These studies, performed almost 30 years ago, demonstrated the immunogenicity of minor histocompatibility antigens (mHAs), which arise from the estimated tens of thousands of differences in SNPs present between each donor and recipient pair (16). mHAs have been fundamental to our current understanding of the mechanistic basis of the curative potential of HSCT as well as of the potential source of its toxicities. Indeed, when considering the classes of antigens targeted by engrafted donor immune cells, the curative graft-versus-leukemia (GvL) effect can be conceptualized as the result of donor immune responses against mHAs expressed on hematopoietic tissue, including, but not limited to, epitopes with hematopoietic tissue restriction. Likewise, the pathogenesis of graft-versus-host disease (GvHD) may be understood as donor-derived immune responses directed against mHAs that are broadly expressed across tissues, or at least on GvHD-affected target tissues (Figure 1A).

The first evidence that $\mathrm{T}$ cells directed against mHAs could potently eradicate leukemic cells came from in vitro studies of $\mathrm{T}$ cells specific for the HLA-A*02:01-restricted HA-1 and HA-2 epitopes and later in a leukemia mouse model treated with HA-1-specific T cells $(17,18)$. HA-1, a SNP of the gene encoding Rho GTPase-activating protein 45 , was initially believed to be a 
Table 1. Ongoing trials targeting neoantigens and minor histocompatibility antigens in blood malignancies

$\begin{array}{llll}\text { Approach } \quad \text { Phase/status Dnrollment Regimen } & \text { Disease }\end{array}$

ClinicalTrials.gov

identifier

\begin{tabular}{|c|c|c|c|c|c|}
\hline \multicolumn{6}{|c|}{ Approaches based on single-treatment modalities } \\
\hline Vaccination & Phase II, recruiting & 105 & DC/AML fusion vaccine vs. observation & AML achieving CTX-induced CR & NCT03059485 \\
\hline Vaccination & Phase I, recruiting & 30 & Personalized long-peptide neoantigen vaccine & Smoldering multiple myeloma & NCT03631043 \\
\hline Vaccination & Phase I, not yet recruiting & 20 & $\begin{array}{l}\text { Personalized long-peptide neoantigen } \\
\text { cancer vaccine (NeoVax) }\end{array}$ & Grade I-IIIA follicular lymphoma & NCT03361852 \\
\hline ICB & Phase II, recruiting & 34 & Pembrolizumab & MPN & NCT03065400 \\
\hline ACT & Phase I, recruiting & 12 & $\begin{array}{l}\text { Autologous T cells immunized ex vivo with } \\
\text { personal neoantigens (PACTN) }\end{array}$ & MDS & NCT03258359 \\
\hline \multicolumn{6}{|l|}{ Combinatorial approaches } \\
\hline Vaccination + ICB & Phase II, recruiting & 25 & $\mathrm{DC} /$ myeloma fusion vaccine + nivolumab & Relapsed multiple myeloma & NCT03782064 \\
\hline Vaccination after HSCT & Phase I/II, recruiting & 10 & $\begin{array}{l}\text { mHA-loaded PD-L1/PD-L2- } \\
\text { silenced DC vaccine }\end{array}$ & Hematological malignancies after HSCT & NCT02528682 \\
\hline Vaccination after HSCT & Phase I, recruiting & 45 & DC/AML fusion vaccine $+/-$ decitabine & AML after HSCT & NCT03679650 \\
\hline ICB after HSCT & Phase I, recruiting & 55 & Ipilimumab and/or nivolumab after HSCT & Relapsed or high-risk AML/MDS after HSCT & NCT03600155 \\
\hline $\mathrm{ICB}+\mathrm{HMA}$ & Phase I, recruiting & 48 & $\begin{array}{l}\text { Ipilimumab and decitabine after HSCT or } \\
\text { without HSCT }\end{array}$ & $\begin{array}{l}\text { Relapsed/refractory MDS or AML after HSCT } \\
\text { and transplant-naive }\end{array}$ & NCT02890329 \\
\hline ACT after HSCT & Phase I/II, not recruiting & 20 & $\begin{array}{l}\text { mHA-specific donor-derived T cells (GLIDE } \\
\text { 201/44) }\end{array}$ & Hematological malignancies after HSCT & NCT03091933 \\
\hline ACT after HSCT & Phase I, recruiting & 24 & $\begin{array}{l}\text { HA-1-specific CD8 } 8^{+} \text {and } \mathrm{CD}^{+} \text {donor } \\
\text { memory T cells }\end{array}$ & $\begin{array}{l}\text { Relapsed or refractory acute leukemia } \\
\text { after HSCT }\end{array}$ & NCT03326921 \\
\hline
\end{tabular}

CR, complete remission; CTX, chemotherapy; HMA, hypomethylating agent; IGHV, Ig heavy chain gene; PACTN, patient-specific MDS stem cell neoantigens.

contributing factor for GvHD and was originally identified after purification by HPLC and tandem mass spectrometry from a patient-derived EBV-transformed B cell line $(19,20)$. Likewise, HA-2 arises from a SNP in the gene MYO1G (encoding myosin $1 G)$; like HA-1, it is involved in cytoskeletal rearrangement (21, 22). Both mHAs have been the focus of extensive efforts aimed at enhancing GvL because their tissue distribution is restricted to hematopoietic tissue (23). HA-1 and HA-2 differ in MHC binding affinity and in their recognition by $\mathrm{T}$ cells compared with their nonimmunogenic variants, which explains why disparity between donor and recipient at these loci mediates GvL effects (24). Larger retrospective studies have evaluated the association of HA-1 disparity between donor and recipient with clinical outcome: in a cohort of 285 chronic myelogenous leukemia (CML) patients, HA-1 disparity in the presence of acute GvHD correlated favorably with regard to overall survival, relapse-free survival, and risk of relapse (25). Similarly, a multicenter analysis of 849 patients after HSCT across different malignancies demonstrated that mismatch for 10 different mHAs and occurrence of GvHD reduced the likelihood of relapse and increased relapse-free survival as well as overall survival (26).

Given its immunogenicity, various efforts have explored the potential of cellular therapies to target HA-1. Notably, this approach has the potential to be clinically impactful, since $25 \%$ of White patients express both HA-1 and HLA-A ${ }^{*} 02: 01$. One such early example explored the effects of administering donor lymphocyte infusions (DLIs) in the setting of HA-1 and/or HA-2 incompatibility for treatment of post-HSCT disease relapse. Three such patients, two with CML and one with multiple myeloma (MM), achieved complete donor chimerism and remission following cell infusion (27). Dossa et al. proposed an off-theshelf approach for targeting mHAs by developing an HA-1-specific HLA-A ${ }^{*}$ 02:01-defined $\mathrm{T}$ cell receptor (TCR) for adoptive $\mathrm{T}$ cell transfer (ACT) (28).

A growing list of other candidate mHAs with expression limited to hematopoietic tissue has been identified (Figure 2 and Table 2). As an example, Akatsuka et al. identified variants of the $B C L 2 A 1$ gene restricted by HLA-A 24:02 (29). A variant of PANE1 (HLA-A ${ }^{*}$ 3:01) was found to be selectively expressed on resting $\mathrm{CD}_{19}{ }^{+} \mathrm{B}$ cells and B chronic lymphocytic leukemia (B-CLL) cells and therefore a potential therapeutic target for $\mathrm{B}$ cell malignancies (30). As another example, an HLA-B ${ }^{*} 44-$ restricted epitope of $H B-1$, selectively expressed on transformed $B$ cells, was identified in a patient with B cell acute lymphoblastic leukemia (B-ALL) following HSCT, in which HB-1-specific T cells recognized EBVtransformed B cells and B-ALL blasts (31). 
A

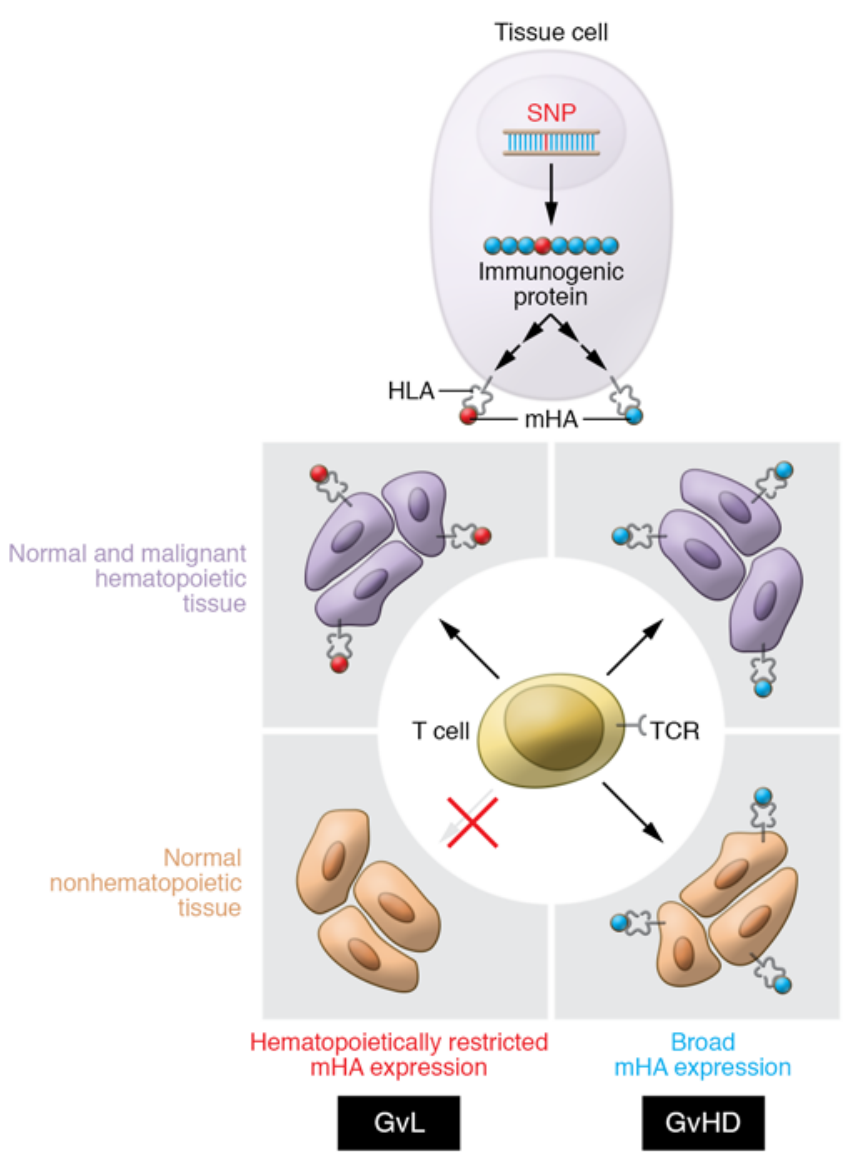

B

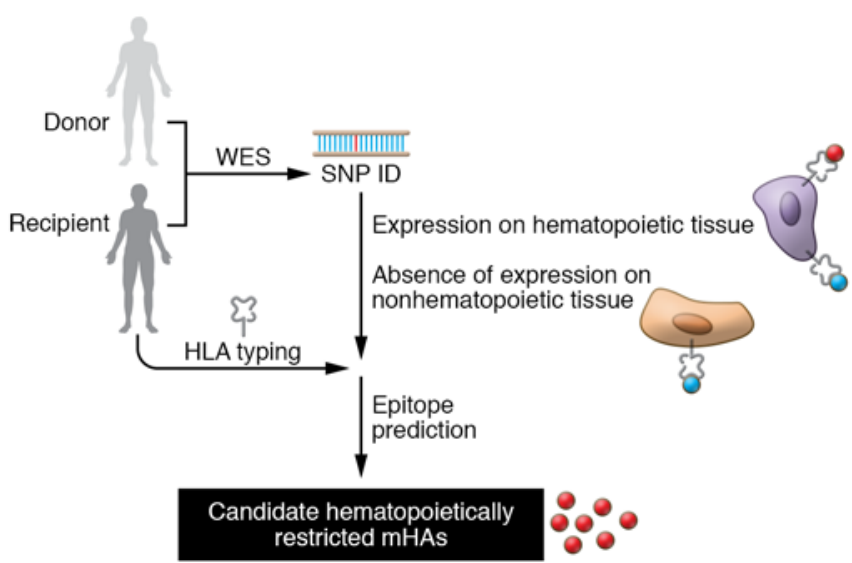

C
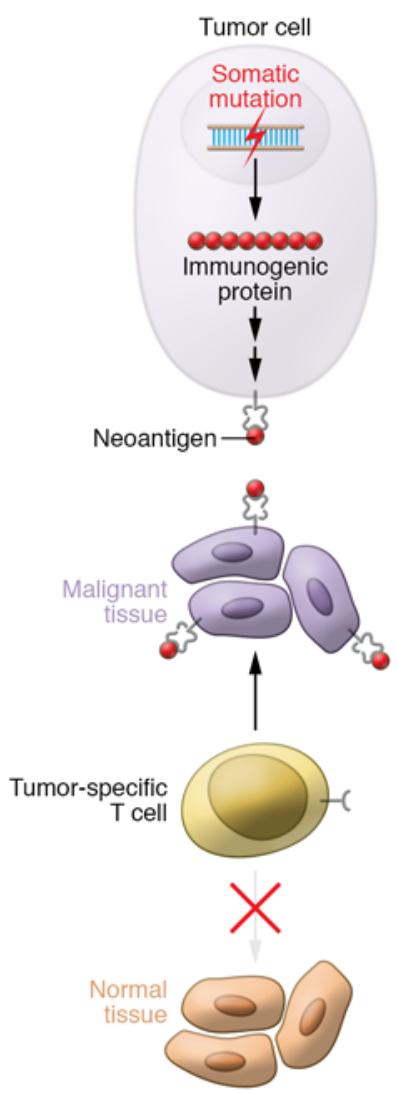

D

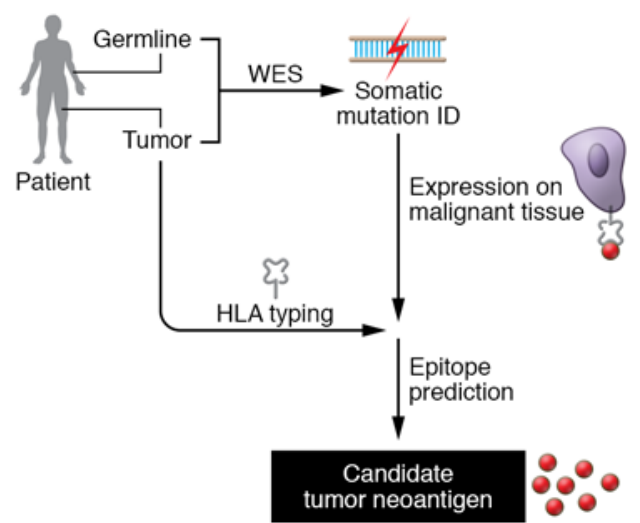

Figure 1. Hematopoietic-restricted mHAs and tumor neoantigens. (A) Differences in SNPs between donor and recipient that give rise to immunogenic epitopes are the basis of mHAs in the context of allogeneic HSCT. While mHAs with hematopoietic tissue restriction are targets for GvL effects, mHAs that are broadly expressed serve as basis for GVHD. (B) Identification of therapeutically relevant mHAs is based on epitope prediction of SNPs and selection of hematopoietically restricted candidates. (C) Tumor-specific neoantigens arise from somatic mutations in the tumor that are immunogenic. Neoantigens are only expressed by tumor cells and therefore are ideal targets for highly specific cellular therapeutic approaches. (D) Identification of neoantigens is based on epitope prediction of immunogenic mutations.

To expand mHA-specific $\mathrm{T}$ cells and target recipient cells, vaccination strategies have been devised. For example, donor-derived DC vaccines pulsed with mHA peptides of LRH-1, UTA2-1, and HA-1 could induce specific T cell responses in patients with MM (32). To improve the efficacy of mHAtargeting DC vaccines, Hobo et al. developed siRNAs for the in vitro knockdown of the checkpoint ligands PD-L1 and
PD-L2, and found that this strategy increased DC-induced mHA-specific T cell expansion (33). A phase I/II trial is currently testing this approach (NCT02528682; ClinicalTrials.gov). Another promising concept has explored the use of an HA-1 vaccine to induce HA-1-specific T cells in HA-1- donors, from whom a vaccine-augmented DLI product targeting mHAs could then be apheresed (34). 
A

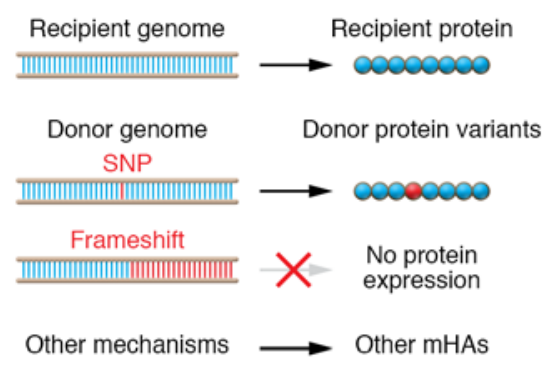

B

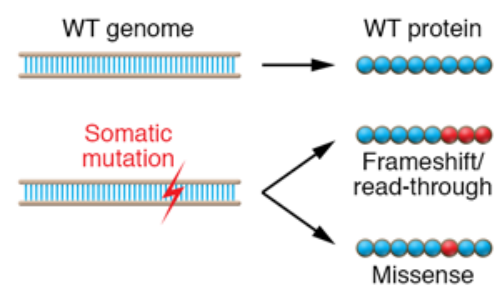

C

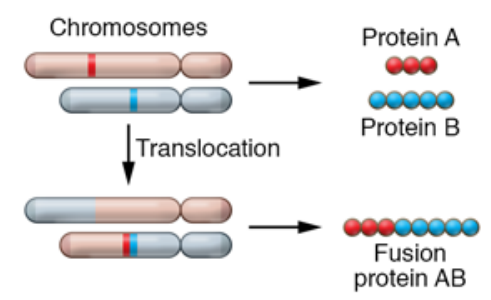

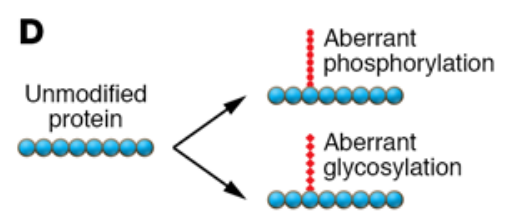

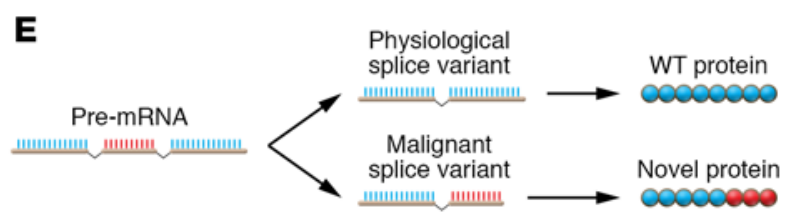

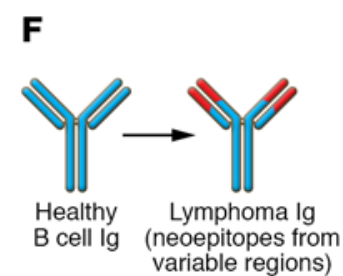

Figure 2. Classes of personal antigen targets in blood malignancies. (A) Minor histocompatibility antigens often arise due to SNPs, resulting in differing physiological protein variants between the donor and the host of allogeneic HSCT. Other mechanisms giving rise to mHAs, such as frameshift mutations, have also been described and are reviewed extensively elsewhere (183). (B and C) Somatic mutations (B) and gene fusions due to chromosomal aberrations (C) give rise to physiologically nonexistent, tumor-specific protein variants. (D) Aberrant posttranslational modifications add neoepitopes to physiological proteins. (E) Alternative splicing results in neojunctions due to altered posttranscriptional processes in tumor cells. (F) Hypervariable Ig regions can be immunogenic, disease-specific epitopes in B cell malignancies.

In recognition of the unique set of mHAs per donorrecipient pair based on the patient's genetics and HLA expression, Warren et al. prospectively isolated mHA-specific $\mathrm{CD} 8^{+} \mathrm{T}$ cells personal to each recipient by coculturing donor-derived $\mathrm{T}$ cells obtained after HSCT with recipient PBMCs and selecting CD8 ${ }^{+}$ clones with cytolytic activity against recipient hematopoietic cells, but not against recipient fibroblasts or donor hematopoietic cells. Five of seven patients who relapsed after HSCT achieved complete remission after receiving salvage chemotherapy and mHA-specific T cells; notably, in three cases, remission occurred only after infusion of mHA-specific $\mathrm{T}$ cells (35). Ultimately, however, all patients relapsed, which was attributed to the short persistence observed of the transferred T cells. In some cases, high-grade GvHD was observed, consistent with the expression of certain targeted mHAs not restricted to hematopoietic tissue.

Moving beyond the classical labor-intensive discovery methods, Granados et al. reported 39 novel candidate mHAs with expression restricted to hematopoietic tissue, identified through proteomic screening of 13 healthy donors and the mining of publicly available RNA-Seq tissue expression data of bone marrow and skin tissue to ascertain hematopoietic restriction (36). Donor-derived $\mathrm{T}$ cells primed against these candidate mHAs are undergoing testing in an ongoing phase I/II clinical trial (NCT03091933). As an alternative approach, Lansford et al. predicted 102 novel leukemia-associated mHAs based on the analysis of SNP alleles identified from a cohort of 101 donorrecipient pairs that were only present in recipients with high predicted HLA-binding affinity and expression restricted to hematopoietic tissues (Figure 1B). Altogether, this approach provides a systematic strategy to identify candidate mHAs as targets for personal vaccination or ACT approaches following HSCT (37).
Tumor neoantigens: optimal tumor antigen targets Neoantigens are novel peptides derived from somatic mutations in malignant cells. Conceptually, they represent ideal tumor antigen targets because of their tumor-restricted expression, hence providing the potential to trigger only disease-specific immune responses without the risk of targeting normal tissues (Figure 1C). Neoantigen-specific $\mathrm{T}$ cell responses may be part of physiological immune surveillance and may underlie normal strategies to augment immunological tumor control (38). Unlike native proteins overexpressed on malignant cells (e.g., WT1 or survivin), or cancer/testis antigens (e.g., MAGE1, PRAME, or NY-ESO-1) that are only expressed on immune-privileged germ cells, neoantigens are not presented in normal tissue and are therefore not subject to central T cell tolerance (39).

The current extensive investigations into tumor neoantigens in the field of cancer immunotherapy have been preceded by a large body of early anecdotal reports supporting the notion that tumor neoantigens are clinically relevant targets of effective antitumor immunity (40-44). However, only with the availability of modern-day sequencing technologies to comprehensively detect the somatic mutations present in primary human cancer specimens and improved epitope prediction, through neural networkbased algorithms, has systematic identification of tumor neoantigens become broadly possible (Figure 1D). Early work using these modern tools to identify tumor neoepitopes was achieved in a study of resistance mutations to imatinib in the driver $B C R-A B L$ in patients with CML. Cai et al. used in silico epitope prediction methods to screen for immunogenic neoepitopes arising from 26 previously described $B C R-A B L$ resistance mutations identified by targeted sequencing, and demonstrated strong $\mathrm{T}$ cell responses against these predicted targets in vitro, including strong responses 
Table 2. Examples from the different classes of personal antigen targets in blood malignancies

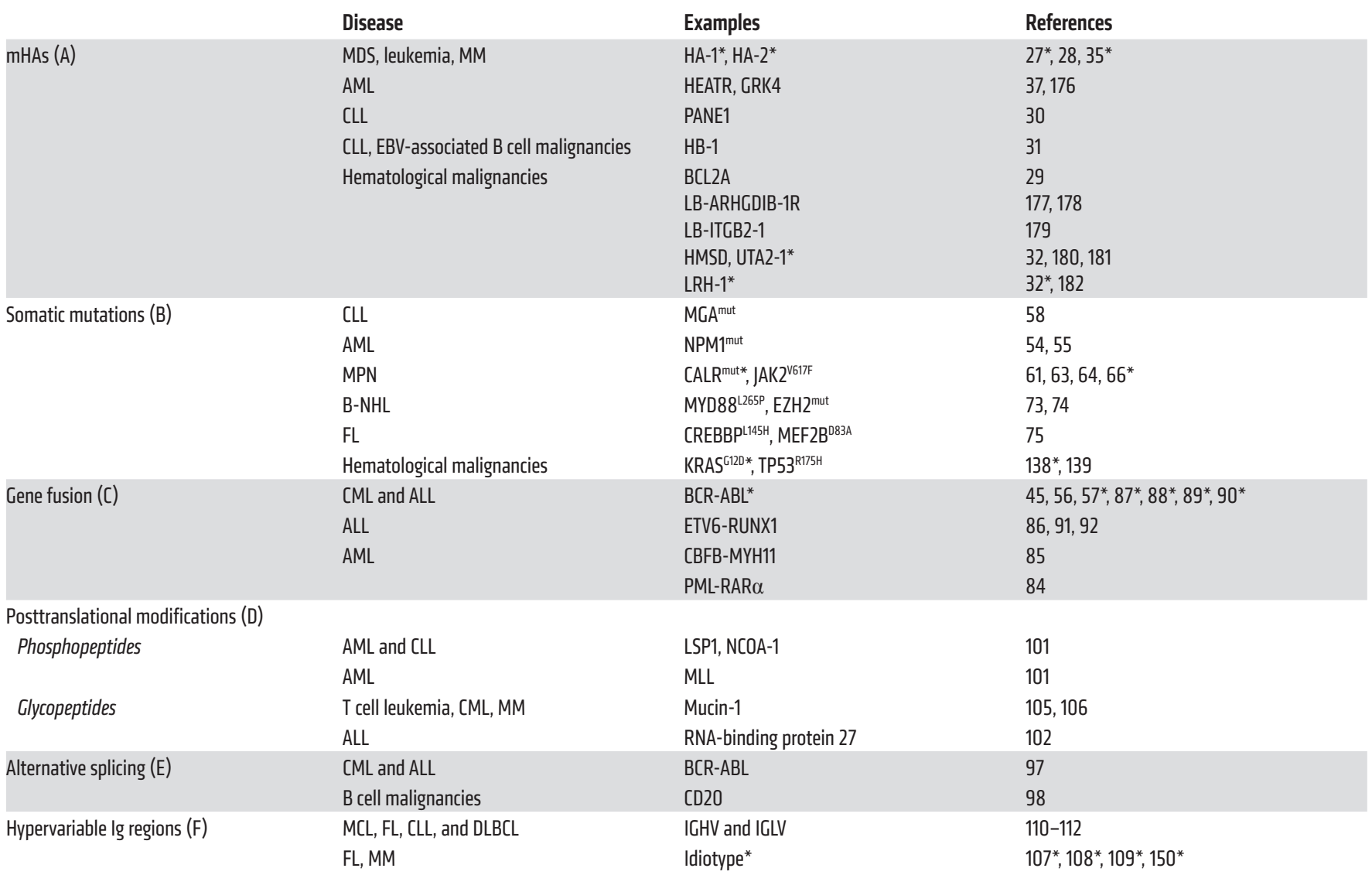

Each class corresponds to mechanistic diagrams in Figure 2, A-F. Asterisks indicate targets that have been clinically tested, along with the respective references. ICLV, Ig light chain variable region gene; MCL, mantle cell lymphoma.

arising following effective HSCT (45). Extending the concept that neoantigen-specific antitumor $\mathrm{T}$ cell responses could be discovered in the setting of effective tumor immunity in blood malignancies, Rajasagi et al. used systematic evaluation of private somatic mutation profiles of 91 CLL samples, identified by whole-exome sequencing (46). They showed the feasibility of consistently predicting immunogenic epitopes arising from missense mutations in CLL and traced the sustained persistence of circulating T cells with specificity for personal neoantigens in long-term survivors following HSCT.

\section{Targeting driver mutation-derived neoantigens in blood malignancies}

Although passenger mutations represent more than $90 \%$ of mutation load per cancer $(47,48)$ and have the potential to be immunogenic $(46,49,50)$, the targeting of driver mutations is a highly strategic approach that reduces the likelihood of immune escape, as these events are critical to the fitness and survival of malignant cells. Many examples of this class of targets in blood malignancies hold great therapeutic promise (Figure 2 and Table 2).

Acute myeloid leukemia. Approximately $30 \%$ of acute myeloid leukemia (AML) patients harbor founding mutations in nucleophosmin (NPM1), making it the most commonly altered gene in this disease (51). NPM1 ${ }^{\text {mut }}$ gives rise to a 4-bp frameshift mutation in exon 12 with an alternative reading frame at the C-terminus, leading to altered cytoplasmic localization. Two HLA-A ${ }^{*} 02: 01-$ restricted $\mathrm{NPM} 1^{\text {mut }}$ neoepitopes were first reported to generate clinically relevant $\mathrm{T}$ cell responses in an AML patient with molecular relapse who received DLI and subsequently achieved molecular remission (52). In an evaluation of 25 patients, patients displaying NPM1 ${ }^{\text {mut }}$-specific $\mathrm{T}$ cell responses against these epitopes had superior survival compared with those without (53). Forghieri et al. tracked spontaneous appearance and persistence of $\mathrm{NPM} 1^{\text {mut }}$ specific T cells in 31 AML patients, and 4 of 5 patients without NPM1 ${ }^{\text {mut }}$-specific $\mathrm{T}$ cells relapsed eventually (54). As preclinical studies to develop ACT against NPM1 ${ }^{\text {mut }}$, van der Lee et al. transduced an HLA-A ${ }^{*}$ 02:01 TCR specific for NPM1 ${ }^{\text {mut }}$ into T cells from healthy donors. These transgenic $\mathrm{T}$ cells showed in vitro activity against AML blasts and in a leukemia mouse model (55).

Acute lymphoblastic leukemia. Like patients with CML, patients with Philadelphia chromosome-positive $\left(\mathrm{Ph}^{+}\right)$ALL have detectable $\mathrm{T}$ cells with specificity for BCR-ABL. In a long-term follow-up study, Riva et al. highlighted the role of $\mathrm{T}$ cell-mediated tumor surveillance by demonstrating an inverse correlation between minimal residual disease levels and $\mathrm{T}$ cell activity against BCR-ABL. Patients who relapsed lost BCR-ABL-specific T cell immunity (56). 
A

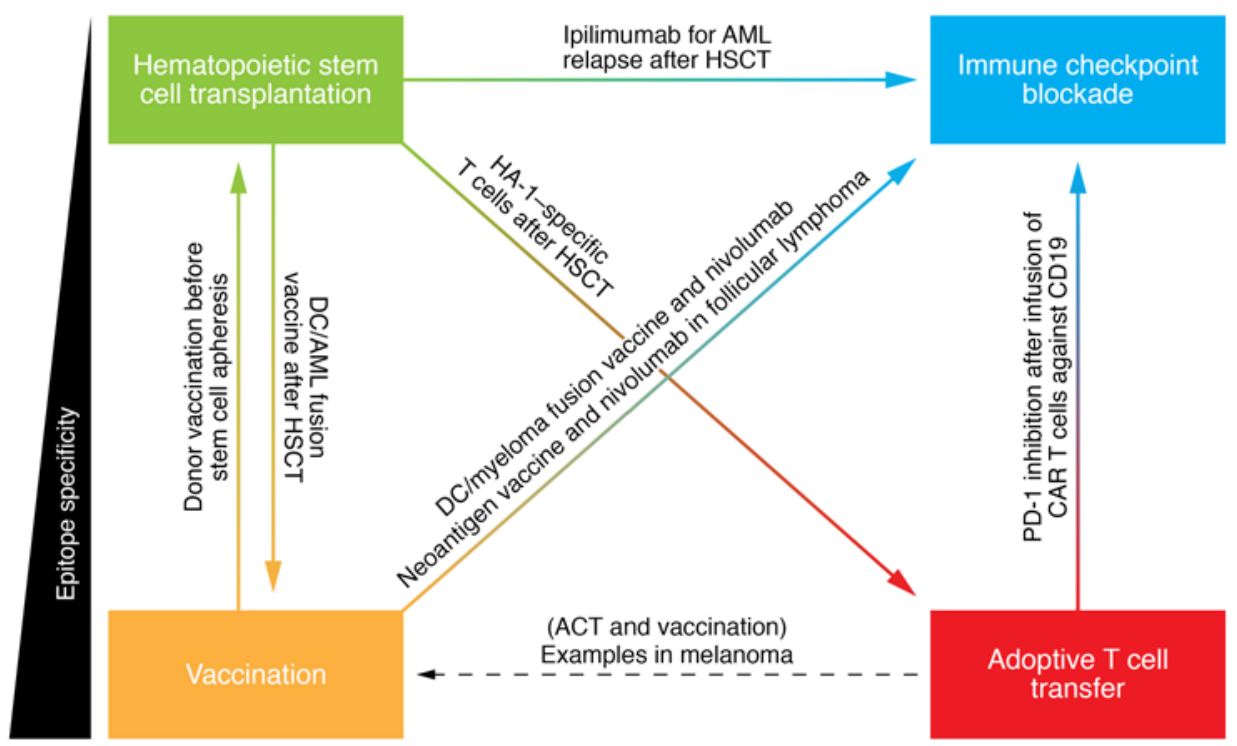

B

Hematopoietic stem cell transplantation
Transfer of normal donor immunity
Reprogramming of the immune microenvironment
Coordination of cellular and humoral antitumor immunity
\[ \text { Vaccination } \]
Increases breadth and diversity of antitumor immunity
Generates de novo tumor-specific T cell responses
Amplifies existing tumor-specific T cell responses

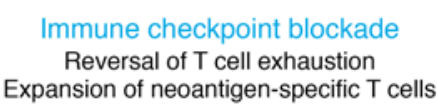

Adoptive T cell transfer

Provides high quantities of antigen-specific T cells

Figure 3. Therapeutic strategies for targeting neoantigens and minor histocompatibility antigens. (A) Modalities targeting neoantigens and mHAs can be classified as those with lesser (e.g., allogeneic HSCT or ICB) or higher degrees of epitope specificity (e.g., ACT or vaccination approaches). Examples of combinatorial approaches of these modalities are shown. (B) Mechanisms underlying each individual therapeutic modality.

To therapeutically exploit BCR-ABL-specific T cells, Comoli et al. reported the ex vivo expansion of autologous or allogeneic $\mathrm{T}$ cells using DCs pulsed with BCR-ABL ${ }^{\mathrm{p} 190}$ peptides. Three heavily pretreated $\mathrm{Ph}^{+} \mathrm{ALL}$ patients with relapsed disease achieved durable molecular or hematological remission after infusion of such expanded BCR-ABL-specific T cells in combination with tyrosine kinase inhibitors (57), providing demonstration of the activity of such an approach.

Chronic lymphocytic leukemia. Hu, Anandappa, et al. (58) predicted immunogenic mutations in $M G A$, a known driver recurrently mutated in high-risk CLL (59). HLA-A ${ }^{\star} 02: 01 \mathrm{~T}$ cells specific for $\mathrm{MGA}^{\mathrm{mut}}$ could be isolated from healthy donors. A TCR was identified that selectively recognizes mutated MGA, thereby offering a potential basis for a $\mathrm{T}$ cell-based therapy directed at $\mathrm{MGA}^{\text {mut }}(58)$.

Myeloproliferative neoplasms. Myeloproliferative neoplasms (MPNs) often harbor immunogenic driver mutations such as BCR-ABL, JAK2 ${ }^{\mathrm{V} 617 \mathrm{~F}}$, mutated calreticulin (CALR $^{\mathrm{mut}}$ ), or $\mathrm{MPL}^{\mathrm{W} 515 \mathrm{~K} / \mathrm{L} / \mathrm{A}}$. HSCT has been clinically successful in many JAK2 ${ }^{\mathrm{V} 617 \mathrm{~F}}$-mutated patients $(60)$. $\mathrm{CD}^{+} \mathrm{T}$ cells with higher binding affinity for JAK2 $2^{\mathrm{V} 617 \mathrm{~F}}$ than for JAK2 ${ }^{\mathrm{WT}}$, which preferentially lyse cells homozygous for JAK2 ${ }^{\mathrm{V} 617 \mathrm{~F}}$, have been identified from healthy donors (61). Notably, JAK2 ${ }^{\mathrm{V} 617 \mathrm{~F}}$-mutated cells in patients with MPNs have been found to express increased levels of PD-L1, suggesting a potential synergy of a $\mathrm{T}$ cell-based approach against JAK2 ${ }^{\mathrm{V} 617 \mathrm{~F}}$ in combination with PD-1 blockade (62).

Mutated calreticulin is a driver mutation in $30 \%$ of patients with JAK ${ }^{\text {WT }}$ essential thrombocythemia and primary myelofibrosis. Calreticulin exon 9 mutations (CALR ${ }^{\text {mut}}$ ) have been characterized as 1-bp frameshift mutations that impair peptide loading to MHC I and give rise to HLA II-restricted immunogenic neoepitopes that can be targeted by cytotoxic CD $4^{+} \mathrm{T}$ cells (63-65). A phase I vaccination trial with $\mathrm{CALR}^{\text {mut }}$ peptides is ongoing (NCT03566446). Cimen Bozkus et al. demonstrated that CALR ${ }^{\text {mut }}$ specific $\mathrm{T}$ cells have increased immune checkpoint expression, thus providing a rationale for PD- 1 inhibition in this disease setting, currently under investigation in a phase II trial probing pembrolizumab in advanced MPNs including CALR ${ }^{\mathrm{WT}}$ and CALR ${ }^{\mathrm{mut}}$ patients (NCT03065400) (66). As for MPL, while up to 17 neoepitopes arising from the $\mathrm{W} 515^{\mathrm{K} / \mathrm{L} / \mathrm{A}}$ mutation have been predicted (67), it has not yet been demonstrated whether these are truly immunogenic. However, this will be crucial given that Tubb et al. failed to detect processing or presentation of a number of putative HLA I-restricted CALR ${ }^{\text {mut }}$ neoepitopes (68).

Non-Hodgkin lymphoma. Among B cell non-Hodgkin lymphomas (B-NHLs), the driver mutations in MYD88 and EZH2 (in diffuse large B cell lymphoma [DLBCL], Waldenström's macroglobulinemia, follicular lymphoma [FL]) have been pre- 
dicted to generate neoepitopes (69-72). Nielsen et al. identified $\mathrm{T}$ cells specific for MYD88 ${ }^{\mathrm{L} 265 \mathrm{P}}$ and $\mathrm{EZH} 2^{\mathrm{Y} 641 \mathrm{~N}}$ with preferential binding affinity for the mutated protein. However, these $\mathrm{T}$ cells have a low prevalence among healthy individuals and were not detectable in two patients with MYD88 ${ }^{\mathrm{L} 265 \mathrm{P}}$-mutated lymphoma, suggesting that absence of neoepitope-specific $\mathrm{T}$ cell responses may contribute to lymphomagenesis (73). Nelde et al. similarly detected $\mathrm{T}$ cell responses against MYD88 ${ }^{\mathrm{L} 265 \mathrm{P}}$ in only 1 of 22 patients with MYD88 $8^{\mathrm{L} 265 \mathrm{P}}$-mutated lymphoma. In contrast, $\mathrm{T}$ cells specific for MYD88 ${ }^{\mathrm{L} 265 \mathrm{P}}$ could be induced in vitro using naive $\mathrm{T}$ cells obtained from healthy donors or from one patient with CLL (74). For FL, the immunogenicity of the putative driver mutations $C R E B B P$ and $M E F 2 B$ has been evaluated. Nielsen et al. found mutation-specific T cells in 3 of $13 \mathrm{FL}$ patients at low frequencies in peripheral blood that could be expanded in vitro (75). Taken together, $\mathrm{T}$ cell immunity against driver mutations in B-NHL is inducible in some patients, suggesting a window of opportunity for $\mathrm{T}$ cell-based immunotherapies.

\section{Classes of neoantigens not derived from somatic mutations}

In light of the therapeutic success of immune-based therapies in blood malignancies and their low mutational burden, other groups of antigens likely play a central role. This is illustrated by mass spectrometry-based analyses of the HLA ligandome in MM, AML, and CLL, which have identified disease-specific nonmutated peptides as targets of $\mathrm{T}$ cell responses (76-78). Models and examples of these targets are given in Figure 2 and Table 2.

Gene fusions. Gene fusions have the potential to give rise to immunogenic neoepitopes, as has been recently demonstrated in head and neck cancers (79). Gene fusions often arise from chromosomal translocations and are a hallmark of hematological malignancies (51, 80-83). Although immunogenic neoantigens arising from gene fusions have long been described in hematological neoplasms $(45,84-86)$, only BCR-ABL has been targeted therapeutically using vaccination approaches, which were able to induce specific $\mathrm{T}$ cell responses (87-90). Efforts to develop a $\mathrm{T}$ cell-based therapy directed at a particular neoepitope arising from ETV6-RUNX1, the most common fusion gene in childhood B-ALL, were stopped because of a lack of endogenous processing (91). Recently, more immunogenic neoepitopes deriving from ETV6-RUNX1 have been uncovered $(92,93)$. Given the central role of gene fusions in the pathogenesis of hematological malignancies, other neoepitopes from this group are likely candidates as therapeutic targets.

Alternative splicing. Alternative splicing can lead to entirely novel and disease-specific immunogenic neojunctions found in many cancer entities (94). Since alternative splicing is common among blood malignancies, neoantigens arising from neojunctions may harbor great therapeutic potential $(95,96)$. The first evidence for neoantigens deriving from alternative splicing was observed in the setting of CML. T cells specific for alternative splice variants of $B C R-A B L$ obtained from $C M L$ patients were able to lyse blasts (97). In many B cell lymphomas, a splice variant of $C D 2 O$ is commonly expressed and $\mathrm{T}$ cell responses against $\mathrm{CD} 2 \mathrm{O}^{\mathrm{D} 393}$ are detectable in patients. In a mouse model, Vauchy et al. could induce $\mathrm{CD} 2 \mathrm{O}^{\mathrm{D} 393}$-specific $\mathrm{T}$ cells with a vaccination approach. CD20 ${ }^{\mathrm{D} 393}$ is not found in B cells of healthy individuals and therefore is a promising candidate as a therapeutic target (98).

Posttranslational modifications. Aberrant protein phosphorylation leading to novel phosphopeptides and rewired cell signaling is a fundamental mechanism in blood malignancies and the basis for kinase inhibitors such as imatinib in CML or midostaurin in AML $(99,100)$. Cobbold et al. reported that aberrantly phosphorylated proteins may be immunogenic and can give rise to neoantigens. T cell responses for 95 tumor-specific phosphopeptides were present in healthy individuals, but were reduced in patients with hematological malignancies, hinting at the possibility that phosphopeptide-derived neoantigens play a role in tumor immune surveillance. Consistent with this observation, in 12 patients with AML after HSCT, the reconstituted donor-derived $\mathrm{T}$ cell responses against phosphopeptides were increased (101).

Glycopeptides are proteins characterized by $\beta$ O-linked $\mathrm{N}$-acetylglucosamine (O-GlcNAc). Malaker et al. used mass spectrometry to identify $36 \mathrm{O}-$ GlcNAc-modified peptides as candidate neoantigens in primary leukemia samples. $\mathrm{T}$ cell responses against these glycopeptides, like those against phosphopeptides, were detectable in healthy donors. T cells selectively lysed cells that presented the O-GlcNAc-modified peptides (102). Mucin- 1 is aberrantly glycosylated in solid tumors and hematological malignancies such as MM $(103,104)$. Chimeric antigen receptor (CAR) T cells targeting glycosylated mucin-1 have been developed that specifically kill malignant cells in experimental leukemia models $(105,106)$.

Ig rearrangements. In B-NHL, neoantigens may arise from productive rearrangement and somatic hypermutation within Ig genes, which may induce specific $\mathrm{T}$ cell responses against malignant B cells. Despite this promise, three different phase III trials of disease-specific idiotype (Id) vaccination in FL revealed only modest clinical activity (107-109). Subgroup analyses demonstrated increased progression-free or disease-free survival in patients who received IgM-Id instead of IgG-Id vaccines (107) or displayed an increase of idiotype-specific antibody titers (109).

Idiotype-specific $\mathrm{CD}^{+} \mathrm{T}$ cells able to selectively lyse tumor cells have been isolated from peripheral blood of patients across different B cell malignancies (110). Khodadoust et al. demonstrated that MHC II-restricted presentation of neoantigens arising from Ig rearrangement is common in mantle cell lymphoma. Interestingly, neoantigens from nonsynonymous mutation were not identified in this cohort of 17 patients, possibly reflecting immune editing and low mutation burden in this disease (111). In an analogous fashion, Ig neoantigens were shown to be presented mainly by MHC II in FL, DLBCL, and CLL (112).

\section{Approaches for targeting mHAs and neoantigens therapeutically}

Given that we are now able to systematically predict or identify personal mHAs or tumor antigen targets, diverse avenues for using this information to rationally design therapy tailored to the individual become feasible. In addition to ICB and HSCT, which are broadly immunomodulatory approaches but not highly targeted to specific epitopes, this can be achieved through antigenspecific approaches such as vaccination or by ACT (Figure 3).

$I C B$. The recent clinical availability and potency of ICB agents for the treatment of diverse cancers, and now FDA approvals 
across various indications, have been transformative for the field of cancer immunotherapy (113). Numerous studies in the solidtumor malignancies have revealed the role of neoantigens as targets of responses achieved in diseases harboring high mutational load (11, 114-116). In the blood malignancies, the responses to ICB alone have been largely disappointing, which can be attributed in part to the generally low mutational burdens of these diseases (46). Hodgkin's lymphoma (HL) stands out as a dramatic exception, with overall responses in the relapsed/refractory setting after ASCT of $69 \%$ (117). Response to PD-1 inhibition in HL has been linked to its inherent overexpression of PD-L1 due to amplification of the 9p24.1 locus and expression of latent membrane protein 1 in the case of $\mathrm{EBV}^{+} \mathrm{HL}(118,119)$. Other clear examples of response to ICB in the blood malignancy setting have been described in relapsed extramedullary AML following HSCT, wherein administration of CTLA-4 blockade (with ipilimumab) was demonstrated to induce complete remissions (120). In myelodysplastic syndrome (MDS), single ipilimumab or combination of nivolumab with azacytidine generated clinical responses in 2 of 9 and in 6 of 11 patients, respectively (121).

Vaccines. Vaccination approaches have the potential to increase the number and potency and broaden the diversity of $\mathrm{T}$ cells with specificity against immunizing antigens, which are presented by the target cells. Given the recent approaches that enable systematic identification of hematopoietically restricted mHAs and tumor neoantigens, vaccination presents an attractive strategy to induce naive antigen-specific $\mathrm{T}$ cell responses and generate sustained $\mathrm{T}$ cell memory $(49,122)$. As reviewed below, strategies that enable targeting of these novel antigens can be achieved using wholetumor, DC, and personal antigen-specific vaccines.

Whole tumor cell vaccines have the advantage of providing a broad repertoire of tumor candidate antigens, including neoantigens, and have been tested over the past two decades. In hematological malignancies, access to large representative tissue samples makes this approach highly feasible. One such example is GVAX (GM-CSF-secreting autologous leukemia cell vaccination), which uses irradiated autologous tumor cells engineered to express GM-CSF or combines irradiated autologous tumor cells with GM-CSF-secreting bystander cells (123). An alternate example, which also provides the advantage of presenting a broad range of tumor antigens along with costimulatory signals, is the autologous DC/tumor cell fusion vaccine. Rosenblatt et al. generated a DC/ AML blast fusion vaccine that induced expansion of $\mathrm{T}$ cells specific not only to autologous AML but also to cancer/testis antigens and leukemia-associated antigens. Twelve of 17 patients receiving the vaccine remained in remission with a median of 57 months of follow-up (124). Follow-up trials using this platform are ongoing in the nontransplant (NCT03059485) and post-transplant (NCT03679650) settings.

Personal neoantigen vaccines have been demonstrated to induce neoantigen-specific $\mathrm{T}$ cell responses using synthetic long peptides (49, 50), RNA-based formulations (125), or peptidepulsed DCs (122). Because of the unique set of mutations in every patient, the manufacturing process requires sequencing of a representative tumor sample and germline tissue, identification of tumor-specific neoantigens, and prediction of their HLA binding and selection of promising candidates. This has been extensively reviewed elsewhere $(126,127)$. Personal neoantigen vaccines have been demonstrated to induce strong $\mathrm{T}$ cell responses in solid tumors $(49,50,128,129)$. Among hematological malignancies, phase I trials with personal neoantigen vaccines are being conducted in CLL (NCT03219450), ALL (NCT03559413), MM (NCT03631043), and FL (NCT03361852).

Adoptive $T$ cell transfer. ACT directly provides high quantities of functional $\mathrm{T}$ cells aimed at eliminating malignant cells. This approach relies on $\mathrm{T}$ cells specific for targets expressed selectively on malignant cells. The dramatic successes of CAR T cells directed against CD19 for the B cell malignancies (130), and now against $\mathrm{B}$ cell maturation antigen-expressing (BCMA-expressing) $\mathrm{MM}$ $(131,132)$, provide clear demonstration of the cytotoxic potency of $\mathrm{T}$ cells when they are linked to tumor-expressed antigens. CAR $\mathrm{T}$ cells act independently of HLA and may be further optimized with costimulatory receptors. However, thus far, their in vivo persistence is limited, remissions are short-lived as a result of antigen downregulation, and on-target toxicities have been common (133). As a promising alternative approach to targeting tumor-expressed antigens, Chapuis et al. expanded allogeneic $\mathrm{CD} 8^{+} \mathrm{T}$ cells specific for WT-1. In 4 of 11 advanced cases of acute leukemia, durable complete remissions were achieved that correlated with long-term persistence of WT-1-specific T cells (134). Remarkably, in 12 highrisk patients, no relapse was observed 44 months after prophylactic infusion of WT-1-specific T cells after HSCT (135).

Personalized ACT against neoantigen or mHA targets has been proposed and developed either as antigen-specific cells expanded from tumor-infiltrating lymphocytes (TILs) or as T cells engineered to express neoantigen/mHA-specific TCRs. Examples of the former include ACT targeting neoantigens in melanoma (136) and single cases of cholangiocarcinoma (137) or colorectal cancer (138). An ongoing phase I trial in MDS is testing the effects of autologous T cells that are reinfused after ex vivo coculture with personal neoantigens (NCT03258359). As the manufacture of personal neoantigen-targeting ACT is resource-demanding, the concept of targeting shared neoantigens in this fashion has been actively considered. The identification of HLA-A $02: 01$ NPM1 ${ }^{\text {mut }}$ specific TCRs provides a therapeutic approach targeting a neoantigen frequently found in AML (55). Other examples include TCRs specific for $\mathrm{p} 53^{\mathrm{R} 175 \mathrm{H}}$ and KRAS ${ }^{\mathrm{G} 12 \mathrm{D}}$, mutations shared among blood malignancies $(138,139)$. As an example of ACT targeting a common mHA, HA-1-specific T cells are currently undergoing testing in a phase I trial in patients with acute leukemia relapse following HSCT (NCT03326921) (28).

\section{Combinatorial genomics-directed therapeutic modalities to overcome resistance mechanisms}

While therapeutic efforts directed at targeting neoantigens have shown promising activity, there has been increasing recognition of the negative impact of immune escape mechanisms, which include increased checkpoint expression on mHA-specific $\mathrm{T}$ cells (140), loss of HLA class I molecules (138), downregulation of HLA class II molecules (141), and loss of neoantigen or mHA expression $(35,142,143)$. Thus, several clinical trials are already under way that combine complementary tumor-directed immune-based treatment strategies to overcome resistance mechanisms (Figure 3A). 
The post-transplant setting has long been recognized as an advantageous platform for immunotherapy, insofar as donor immune reconstitution overcomes host immunosuppression and can favorably reprogram the immune microenvironment (Figure 3B). The concept that donor-derived leukemia-specific $\mathrm{T}$ cells could be generated by HSCT but that transcriptional signatures of $\mathrm{T}$ cell exhaustion were present in marrow-infiltrating $\mathrm{T}$ cells in the setting of leukemic relapse was demonstrated in studies of patients with CML following HSCT. Furthermore, this phenotype could be reversed in association with effective DLI therapy (144). This work naturally sets the stage for combining HSCT with ICB therapy. As mentioned above, the combination of CTLA-4 blockade with HSCT to effectively treat AML relapse has provided a notable example of responsiveness of hematological malignancies to ICB (120). Ongoing follow-up studies are now aimed at testing ipilimumab in combination with decitabine (NCT02890329) or nivolumab (NCT03600155) for relapsed AML following HSCT. On the other hand, varying rates of excess GvHDassociated toxicity in the same setting point to mechanistic differences among ICB agents and the impact of parameters such as dosage, previous history of GvHD, or time post-HSCT $(145,146)$.

The early post-transplant setting, with host lymphodepletion and the presence of a favorable homeostatic cytokine milieu for $\mathrm{T}$ cell expansion, has been likewise thought to provide an opportune window for vaccination to induce donor-derived tumor-specific T cells, and thereby enhance GvL (147). Burkhardt et al. observed increased $\mathrm{CD}^{+} \mathrm{T}$ cell reactivity against CLL-associated antigens and effector cytokine production in 18 patients with advanced CLL after challenge with autologous GVAX administered within the first 4 months after allogeneic HSCT (148). Ho et al. similarly detected tumor-specific immune responses in a pilot study of GVAX after HSCT for patients with advanced AML or MDS, now expanded to a randomized phase II follow-up trial (NCT01773395) (149). With the ability to predict neoantigens and mHAs, one could likewise envision the feasibility of developing vaccines targeting these specific antigens following HSCT. As an alternative approach to boosting donor-derived tumor responses through vaccination with HSCT, Foglietta et al. tested the concept of pre-HSCT donor vaccination. Ten HLA-matched sibling donors received recipientderived MM idiotype vaccines before collection of allografts, and demonstrated that idiotype-specific immune responses can be induced in the donor and transferred into the recipient (150).

In the absence of HSCT, vaccines have been recognized as important adjuncts to ICB, given their ability to induce de novo naive $\mathrm{T}$ cell responses, amplify memory $\mathrm{T}$ cell responses, and broaden the diversity of antitumor $\mathrm{T}$ cells. Indeed, preclinical data have shown the synergistic effects of a DC/myeloma fusion vaccine and PD-1 inhibition (151), with testing of this approach currently under way in a phase II trial (NCT03782064). Given the promising clinical responses to the combination of personal neoantigen vaccination with anti-PD-1 therapy described in a few patients with high-risk melanoma $(49,125)$, this combination is now being formally tested in a series of clinical trials (NCTO2897765, NCT03289962). Early results of these studies have indicated the detection of neoantigen-specific $\mathrm{T}$ cell responses beyond the epitopes provided by the neoantigen vaccine, consistent with on-tumor targeting by the therapy (152). The concept of combining neoantigen vaccines with PD-1 inhibition is now under investigation for patients with FL (NCT03121677).

Suboptimal responses to ACT have been linked to exhaustion of effector cells and their inability to expand in vivo, which may be overcome by combination with ICB or vaccination $(153,154)$. These investigations are active, though still in their infancy. For example, the administration of anti-PD-1 therapy was able to induce clinical responses in 3 of 9 DLBCL and 2 of 4 B-ALL patients refractory or progressive after CAR T cell therapy (155-157). Successful efforts in melanoma combining ACT with vaccinations could be a model for approaches in blood malignancies $(158,159)$.

\section{Outlook}

Personal antigen-directed therapeutic approaches have come a long way since the early days of HSCT and promise to remain a driving force for progress in hematology. The recent breathtaking technological advances have opened doors for a systematic understanding of target antigens $(46,50,58)$, the identities and characteristics of subpopulations of TILs (160-162), and immunological aspects of disease biology (163).

In addition to deeper mechanistic investigation and clinical studies about effective combinatorial immunotherapy, we can expect further exciting developments in the realms of antigen discovery and the engineering of immunotherapy. Neoantigen detection pipelines provide novel candidate target antigens and therefore the opportunity to link TILs to their cognate TCRs (164166). Technologies such as single-T cell paired TCR $\alpha \beta$ sequencing $(167,168)$, mass cytometry, or FACS index sorting (169-171) can provide deeper complex understanding of TIL biology and aid in developing fresh therapeutic strategies directed at candidate target antigens. Using these advances, we are now also able to trace the coevolution of hematological malignancies and their host immune system (172). Likewise, the development of CRISPR/Cas9 gene editing (173), the discovery efforts with genome-wide screens (174), and developments in the area of spatial tissue-based characterization (175) will have important implications for the delivery of novel targets and subsequent engineering of immune responses.

\section{Acknowledgments}

This work was supported by grants from the NIH, National Cancer Institute (U10CA180861-01,1RO1CA155010, and P01CA229092, to CJW). CJW is a Scholar of the Leukemia and Lymphoma Society. We acknowledge support from the Fishman Family Fund. LP is supported by a research fellowship from the German Research Foundation (DFG, PE 3127/1-1).

Address correspondence to: Catherine J. Wu, Department of Medical Oncology, Dana-Farber Cancer Institute, Dana 520C, 44 Binney Street, Boston, Massachusetts 02115, USA. Phone: 617.632.5943; Email: cwu@partners.org.

\footnotetext{
1. Hodi FS, et al. Improved survival with ipilimumab in patients with metastatic melanoma. $N$ Engl J Med. 2010;363(8):711-723.
}
2. Wolchok JD, et al. Overall survival with combined nivolumab and ipilimumab in advanced melanoma. N Engl JMed. 2017;377(14):1345-1356.
3. Hellmann MD, et al. Nivolumab plus ipilimumab in lung cancer with a high tumor mutational burden. N Engl J Med. 2018;378(22):2093-2104. 
4. Younes A, et al. Nivolumab for classical Hodgkin's lymphoma after failure of both autologous stemcell transplantation and brentuximab vedotin: a multicentre, multicohort, single-arm phase 2 trial. Lancet Oncol. 2016;17(9):1283-1294.

5. Bellmunt J, Powles T, Vogelzang NJ. A review on the evolution of PD-1/PD-L1 immunotherapy for bladder cancer: The future is now. Cancer Treat Rev. 2017;54:58-67.

6. Overman MJ, et al. Nivolumab in patients with metastatic DNA mismatch repair-deficient or microsatellite instability-high colorectal cancer (CheckMate 142): an open-label, multicentre, phase 2 study. Lancet Oncol. 2017;18(9):1182-1191.

7. Thorsson V, et al. The immune landscape of cancer. Immunity. 2018;48(4):812-830.e14.

8. Mandal R, et al. The head and neck cancer immune landscape and its immunotherapeutic implications. JCI Insight. 2016;1(17):e89829.

9. Cogdill AP, Andrews MC, Wargo JA. Hallmarks of response to immune checkpoint blockade. Br J Cancer. 2017;117(1):1-7.

10. Snyder A, et al. Genetic basis for clinical response to CTLA-4 blockade in melanoma. N Engl JMed. 2014;371(23):2189-2199.

11. McGranahan N, et al. Clonal neoantigens elicit $\mathrm{T}$ cell immunoreactivity and sensitivity to immune checkpoint blockade. Science. 2016;351(6280):1463-1469.

12. Gubin MM, Artyomov MN, Mardis ER, Schreiber RD. Tumor neoantigens: building a framework for personalized cancer immunotherapy. JClin Invest. 2015;125(9):3413-3421.

13. Bachireddy P, Burkhardt UE, Rajasagi M, Wu CJ. Haematological malignancies: at the forefront of immunotherapeutic innovation. Nat Rev Cancer. 2015;15(4):201-215.

14. Jenq RR, van den Brink MR. Allogeneic haematopoietic stem cell transplantation: individualized stem cell and immune therapy of cancer. Nat Rev Cancer. 2010;10(3):213-221.

15. Kolb HJ. Graft-versus-leukemia effects of transplantation and donor lymphocytes. Blood. 2008;112(12):4371-4383.

16. 1000 Genomes Project Consortium, et al. A global reference for human genetic variation. Nature. 2015;526(7571):68-74.

17. Hambach L, et al. Human cytotoxic T lymphocytes specific for a single minor histocompatibility antigen HA-1 are effective against human lymphoblastic leukaemia in NOD/scid mice. Leukemia. 2006;20(2):371-374.

18. Mutis T, Verdijk R, Schrama E, Esendam B, Brand A, Goulmy E. Feasibility of immunotherapy of relapsed leukemia with ex vivo-generated cytotoxic T lymphocytes specific for hematopoietic system-restricted minor histocompatibility antigens. Blood. 1999;93(7):2336-2341.

19. den Haan JM, et al. The minor histocompatibility antigen HA-1: a diallelic gene with a single amino acid polymorphism. Science. 1998;279(5353):1054-1057.

20. Goulmy E, et al. Mismatches of minor histocompatibility antigens between HLA-identical donors and recipients and the development of graftversus-host disease after bone marrow transplantation. N Engl J Med. 1996;334(5):281-285.

21. Pierce RA, et al. The HA-2 minor histocompat- ibility antigen is derived from a diallelic gene encoding a novel human class I myosin protein. J Immunol. 2001;167(6):3223-3230.

22. Spierings E, Wieles B, Goulmy E. Minor histocompatibility antigens-big in tumour therapy. Trends Immunol. 2004;25(2):56-60.

23. de Bueger M, Bakker A, Van Rood JJ, Van der Woude F, Goulmy E. Tissue distribution of human minor histocompatibility antigens. Ubiquitous versus restricted tissue distribution indicates heterogeneity among human cytotoxic T lymphocyte-defined non-MHC antigens. Jimmunol. 1992;149(5):1788-1794.

24. Bleakley M, Riddell SR. Exploiting T cells specific for human minor histocompatibility antigens for therapy of leukemia. Immunol Cell Biol. 2011;89(3):396-407.

25. Mutis T, et al. Graft-versus-host driven graftversus-leukemia effect of minor histocompatibility antigen HA-1 in chronic myeloid leukemia patients. Leukemia. 2010;24(7):1388-1392.

26. Spierings E, et al. Multicenter analyses demonstrate significant clinical effects of minor histocompatibility antigens on GvHD and GvL after HLA-matched related and unrelated hematopoietic stem cell transplantation. Biol Blood Marrow Transplant. 2013;19(8):1244-1253.

27. Marijt WA, et al. Hematopoiesis-restricted minor histocompatibility antigens HA-1- or HA-2specific $\mathrm{T}$ cells can induce complete remissions of relapsed leukemia. Proc Natl Acad Sci US A. 2003;100(5):2742-2747.

28. Dossa RG, et al. Development of T-cell immunotherapy for hematopoietic stem cell transplantation recipients at risk of leukemia relapse. Blood. 2018;131(1):108-120.

29. Akatsuka $Y$, et al. Identification of a polymorphic gene, BCL2A1, encoding two novel hematopoietic lineage-specific minor histocompatibility antigens. JExp Med. 2003;197(11):1489-1500.

30. Brickner AG, et al. The PANE1 gene encodes a novel human minor histocompatibility antigen that is selectively expressed in B-lymphoid cells and B-CLL. Blood. 2006;107(9):3779-3786.

31. Dolstra $\mathrm{H}$, et al. A human minor histocompatibility antigen specific for B cell acute lymphoblastic leukemia. JExp Med.1999;189(2):301-308.

32. Franssen LE, et al. A phase I/II minor histocompatibility antigen-loaded dendritic cell vaccination trial to safely improve the efficacy of donor lymphocyte infusions in myeloma. Bone Marrow Transplant. 2017;52(10):1378-1383.

33. Hobo W, et al. siRNA silencing of PD-L1 and PD-L2 on dendritic cells augments expansion and function of minor histocompatibility antigen-specific $\mathrm{CD}^{+} \mathrm{T}$ cells. Blood. 2010;116(22):4501-4511.

34. Inman CF, et al. Vaccination with a DNA and MVA 'prime-boost' regimen induces strong CD8 $\mathrm{T}$-cell responses against the immunodominant minor histocompatibility antigen, $\mathrm{HA}-1$ : results of a first-in-man phase I clinical trial. Blood. 2017;130(1 suppl):1908.

35. Warren EH, et al. Therapy of relapsed leukemia after allogeneic hematopoietic cell transplantation with T cells specific for minor histocompatibility antigens. Blood. 2010;115(19):3869-3878. 36. Granados DP, et al. Proteogenomic-based dis- covery of minor histocompatibility antigens with suitable features for immunotherapy of hematologic cancers. Leukemia. 2016;30(6):1344-1354.

37. Lansford JL, et al. Computational modeling and confirmation of leukemia-associated minor histocompatibility antigens. Blood $\mathrm{Adv}$. 2018;2(16):2052-2062.

38. Schumacher TN, Schreiber RD. Neoantigens in cancer immunotherapy. Science. 2015;348(6230):69-74.

39. Anguille S, Van Tendeloo VF, Berneman ZN. Leukemia-associated antigens and their relevance to the immunotherapy of acute myeloid leukemia. Leukemia. 2012;26(10):2186-2196.

40. Mandelboim O, Berke G, Fridkin M, Feldman M, Eisenstein M, Eisenbach L. CTL induction by a tumour-associated antigen octapeptide derived from a murine lung carcinoma. Nature. 1994;369(6475):67-71.

41. Wölfel T, et al. A p16INK4a-insensitive CDK4 mutant targeted by cytolytic T lymphocytes in a human melanoma. Science. 1995;269(5228):1281-1284.

42. Coulie PG, et al. A mutated intron sequence codes for an antigenic peptide recognized by cytolytic T lymphocytes on a human melanoma. Proc Natl Acad Sci U S A. 1995;92(17):7976-7980.

43. Robbins PF, et al. A mutated $\beta$-catenin gene encodes a melanoma-specific antigen recognized by tumor infiltrating lymphocytes. J Exp Med. 1996;183(3):1185-1192.

44. Mandruzzato S, Brasseur F, Andry G, Boon T, van der Bruggen P. A CASP-8 mutation recognized by cytolytic T lymphocytes on a human head and neck carcinoma. JExp Med. 1997;186(5):785-793.

45. Cai A, et al. Mutated BCR-ABL generates immunogenic T-cell epitopes in CML patients. Clin Cancer Res. 2012;18(20):5761-5772.

46. Rajasagi M, et al. Systematic identification of personal tumor-specific neoantigens in chronic lymphocytic leukemia. Blood. 2014;124(3):453-462.

47. Sjöblom T, et al. The consensus coding sequences of human breast and colorectal cancers. Science. 2006;314(5797):268-274.

48. Greenman C, et al. Patterns of somatic mutation in human cancer genomes. Nature. 2007;446(7132):153-158.

49. Ott PA, et al. An immunogenic personal neoantigen vaccine for patients with melanoma. Nature. 2017;547(7662):217-221.

50. Keskin DB, et al. Neoantigen vaccine generates intratumoral T cell responses in phase Ib glioblastoma trial. Nature. 2019;565(7738):234-239.

51. Papaemmanuil E, et al. Genomic classification and prognosis in acute myeloid leukemia. $N$ Engl JMed. 2016;374(23):2209-2221.

52. Hofmann S, et al. Donor lymphocyte infusion induces polyspecific CD8(+) T-cell responses with concurrent molecular remission in acute myeloid leukemia with NPM1 mutation. J Clin Oncol. 2013;31(3):e44-e47.

53. Greiner J, et al. Immune responses against the mutated region of cytoplasmatic NPM1 might contribute to the favorable clinical outcome of AML patients with NPM1 mutations (NPM1mut). Blood. 2013;122(6):1087-1088.

54. Forghieri F, et al. Characterization and dynamics of specific T cells against nucleophosmin-1 
(NPM1)-mutated peptides in patients with NPM1-mutated acute myeloid leukemia. Oncotarget. 2019;10(8):869-882.

55. van der Lee DI, et al. Mutated nucleophosmin 1 as immunotherapy target in acute myeloid leukemia. JClin Invest. 2019;129(2):774-785.

56. Riva G, et al. Emergence of BCR-ABL-specific cytotoxic T cells in the bone marrow of patients with $\mathrm{Ph}^{+}$acute lymphoblastic leukemia during long-term imatinib mesylate treatment. Blood. 2010;115(8):1512-1518.

57. Comoli P, et al. BCR-ABL-specific T-cell therapy in $\mathrm{Ph}+\mathrm{ALL}$ patients on tyrosine-kinase inhibitors. Blood. 2017;129(5):582-586.

58. $\mathrm{Hu} \mathrm{Z}$, et al. A cloning and expression system to probe T-cell receptor specificity and assess functional avidity to neoantigens. Blood. 2018;132(18):1911-1921.

59. Landau DA, et al. Mutations driving CLL and their evolution in progression and relapse. Nature. 2015;526(7574):525-530.

60. Kröger N, et al. Monitoring of the JAK2-V617F mutation by highly sensitive quantitative realtime PCR after allogeneic stem cell transplantation in patients with myelofibrosis. Blood. 2007;109(3):1316-1321.

61. Holmström MO, et al. The JAK2V617F mutation is a target for specific $\mathrm{T}$ cells in the JAK2V617F-positive myeloproliferative neoplasms. Leukemia. 2017;31(2):495-498.

62. Prestipino A, et al. Oncogenic JAK2 ${ }^{\mathrm{V} 617 \mathrm{~F}}$ causes PD-L1 expression, mediating immune escape in myeloproliferative neoplasms. Sci Transl Med. 2018;10(429):eaam7729.

63. Holmström MO, Riley CH, Svane IM, Hasselbalch HC, Andersen MH. The CALR exon 9 mutations are shared neoantigens in patients with CALR mutant chronic myeloproliferative neoplasms. Leukemia. 2016;30(12):2413-2416.

64. Holmström MO, et al. The calreticulin (CALR) exon 9 mutations are promising targets for cancer immune therapy. Leukemia. 2018;32(2):429-437.

65. Arshad N, Cresswell P. Tumor-associated calreticulin variants functionally compromise the peptide loading complex and impair its recruitment of MHC-I. J Biol Chem. 2018;293(25):9555-9569.

66. Cimen Bozkus C, et al. Immune checkpoint blockade enhances shared neoantigen-induced T-cell immunity directed against mutated calreticulin in myeloproliferative neoplasms. Cancer Discov. 2019;9(9):1192-1207.

67. Schischlik F, et al. Mutational landscape of the transcriptome offers putative targets for immunotherapy of myeloproliferative neoplasms. Blood. 2019;134(2):199-210.

68. Tubb VM, et al. Isolation of T cell receptors targeting recurrent neoantigens in hematological malignancies. J Immunother Cancer. 2018;6(1):70.

69. Ngo VN, et al. Oncogenically active MYD88 mutations in human lymphoma. Nature. 2011;470(7332):115-119.

70. Varettoni M, et al. Prevalence and clinical significance of the MYD88 (L265P) somatic mutation in Waldenstrom's macroglobulinemia and related lymphoid neoplasms. Blood. 2013;121(13):2522-2528.

71. Bödör C, et al. EZH2 mutations are frequent and represent an early event in follicular lymphoma. Blood. 2013;122(18):3165-3168.

72. Morin RD, et al. Somatic mutations altering EZH2 (Tyr641) in follicular and diffuse large B-cell lymphomas of germinal-center origin Nat Genet. 2010;42(2):181-185.

73. Nielsen JS, et al. Mapping the human T cell repertoire to recurrent driver mutations in MYD88 and EZH2 in lymphoma. Oncoimmunology. 2017;6(7):e1321184.

74. Nelde A, et al. HLA class I-restricted MYD 88 L265P-derived peptides as specific targets for lymphoma immunotherapy. Oncoimmunology. 2017;6(3):e1219825.

75. Nielsen JS, et al. Toward personalized lymphoma immunotherapy: identification of common driver mutations recognized by patient $\mathrm{CD} 8^{+} \mathrm{T}$ cells. Clin Cancer Res. 2016;22(9):2226-2236.

76. Kowalewski DJ, et al. HLA ligandome analysis identifies the underlying specificities of spontaneous antileukemia immune responses in chronic lymphocytic leukemia (CLL). Proc Natl Acad Sci U S A. 2015;112(2):E166-E175.

77. Berlin C, et al. Mapping the HLA ligandome landscape of acute myeloid leukemia: a targeted approach toward peptide-based immunotherapy. Leukemia. 2015;29(3):647-659.

78. Walz S, et al. The antigenic landscape of multiple myeloma: mass spectrometry (re)defines targets for T-cell-based immunotherapy. Blood. 2015;126(10):1203-1213.

79. Yang $\mathrm{W}$, et al. Immunogenic neoantigens derived from gene fusions stimulate $\mathrm{T}$ cell responses. Nat Med. 2019;25(5):767-775.

80. Moorman AV, et al. A novel integrated cytogenetic and genomic classification refines risk stratification in pediatric acute lymphoblastic leukemia. Blood. 2014;124(9):1434-1444.

81. Strati P, Shanafelt TD. Monoclonal B-cell lymphocytosis and early-stage chronic lymphocytic leukemia: diagnosis, natural history, and risk stratification. Blood. 2015;126(4):454-462.

82. Miles RR, Shah RK, Frazer JK. Molecular genetics of childhood, adolescent and young adult non-Hodgkin lymphoma. Br J Haematol. 2016;173(4):582-596.

83. Quintás-Cardama A, Cortes J. Molecular biology of bcr-abl1-positive chronic myeloid leukemia. Blood. 2009;113(8):1619-1630.

84. Gambacorti-Passerini C, Grignani F, Arienti F, Pandolfi PP, Pelicci PG, Parmiani G. Human CD4 lymphocytes specifically recognize a peptide representing the fusion region of the hybrid protein $\mathrm{pml} / \mathrm{RAR}$ alpha present in acute promyelocytic leukemia cells. Blood.1993;81(5):1369-1375

85. Biernacki MA, et al. Identifying leukemia-specific neoepitopes from next-generation sequencing data to develop targeted immunotherapy for pediatric acute myeloid leukemiaig. Biol Blood Marrow Transplant. 2016;22(3):S19.

86. Yotnda $\mathrm{P}$, et al. Cytotoxic $\mathrm{T}$ cell response against the chimeric ETV6-AML1 protein in childhood acute lymphoblastic leukemia. J Clin Invest. 1998;102(2):455-462.

87. Westermann J, et al. Vaccination with autologous non-irradiated dendritic cells in patients with bcr/abl ${ }^{+}$chronic myeloid leukaemia. Br J Haematol. 2007;137(4):297-306.
88. Cathcart K, et al. A multivalent bcr-abl fusion peptide vaccination trial in patients with chronic myeloid leukemia. Blood. 2004;103(3):1037-1042.

89. Bocchia M, et al. Effect of a p210 multipeptide vaccine associated with imatinib or interferon in patients with chronic myeloid leukaemia and persistent residual disease: a multicentre observational trial. Lancet. 2005;365(9460):657-662.

90. Rojas JM, Knight K, Wang L, Clark RE. Clinical evaluation of BCR-ABL peptide immunisation in chronic myeloid leukaemia: results of the EPIC study. Leukemia. 2007;21(11):2287-2295.

91. Popovic J, Li LP, Kloetzel PM, Leisegang M, Uckert W, Blankenstein T. The only proposed T-cell epitope derived from the TEL-AML1 translocation is not naturally processed. Blood. 2011;118(4):946-954.

92. Chang TC, et al. The neoepitope landscape in pediatric cancers. Genome Med. 2017;9(1):78.

93. Zamora AE, et al. Pediatric patients with acute lymphoblastic leukemia generate abundant and functional neoantigenspecific $\mathrm{CD}^{+} \mathrm{T}$ cell responses. Sci Transl Med. 2019;11(498):eaat8549.

94. Kahles A, et al. Comprehensive analysis of alternative splicing across tumors from 8,705 patients. Cancer Cell. 2018;34(2):211-224.e6.

95. Wang L, et al. Transcriptomic characterization of SF3B1 mutation reveals its pleiotropic effects in chronic lymphocytic leukemia. Cancer Cell. 2016;30(5):750-763.

96. Wong ACH, Rasko JEJ, Wong JJ. We skip to work: alternative splicing in normal and malignant myelopoiesis. Leukemia. 2018;32(5):1081-1093.

97. Volpe G, et al. Alternative BCR/ABL splice variants in Philadelphia chromosome-positive leukemias result in novel tumor-specific fusion proteins that may represent potential targets for immunotherapy approaches. Cancer Res. 2007;67(11):5300-5307.

98. Vauchy C, et al. CD20 alternative splicing isoform generates immunogenic CD4 helper T epitopes. Int J Cancer. 2015;137(1):116-126.

99. Stone RM, et al. Midostaurin plus chemotherapy for acute myeloid leukemia with a FLT3 mutation. N Engl J Med. 2017;377(5):454-464.

100.Rosti G, Castagnetti F, Gugliotta G, Baccarani M. Tyrosine kinase inhibitors in chronic myeloid leukaemia: which, when, for whom? Nat Rev Clin Oncol. 2017;14(3):141-154.

101. Cobbold M, et al. MHC class I-associated phosphopeptides are the targets of memorylike immunity in leukemia. Sci Transl Med 2013;5(203):203ra125.

102. Malaker SA, et al. Identification of glycopeptides as posttranslationally modified neoantigens in leukemia. Cancer Immunol Res. 2017;5(5):376-384

103. Cloosen S, et al. Cancer specific Mucin-1 glycoforms are expressed on multiple myeloma. $\mathrm{BrJ}$ Haematol. 2006;135(4):513-516.

104.Van Elssen CH, et al. Expression of aberrantly glycosylated Mucin-1 in ovarian cancer. Histopathology. 2010;57(4):597-606.

105. Posey AD, et al. Engineered CAR T cells targeting the cancer-associated Tn-Glycoform of the membrane mucin MUC1 control adenocarcinoma. Immunity. 2016;44(6):1444-1454. 
106. Wilkie S, et al. Retargeting of human T cells to tumor-associated MUC1: the evolution of a chimeric antigen receptor. J Immunol. 2008;180(7):4901-4909.

107. Schuster SJ, et al. Vaccination with patient-specific tumor-derived antigen in first remission improves disease-free survival in follicular lymphoma. J Clin Oncol. 2011;29(20):2787-2794.

108. Freedman A, et al. Placebo-controlled phase III trial of patient-specific immunotherapy with mitumprotimut-T and granulocyte-macrophage colony-stimulating factor after rituximab in patients with follicular lymphoma. J Clin Oncol. 2009;27(18):3036-3043.

109. Levy R, et al. Active idiotypic vaccination versus control immunotherapy for follicular lymphoma. JClin Oncol. 2014;32(17):1797-1803.

110.Weng J, et al. Targeting B-cell malignancies through human B-cell receptor specific $\mathrm{CD} 4^{+}$ T cells. Oncoimmunology. 2016;5(11):e1232220.

111. Khodadoust MS, et al. Antigen presentation profiling reveals recognition of lymphoma immunoglobulin neoantigens. Nature. 2017;543(7647):723-727.

112. Khodadoust MS, et al. B-cell lymphomas present immunoglobulin neoantigens. Blood. 2019;133(8):878-881.

113. Wei SC, Duffy CR, Allison JP. Fundamental mechanisms of immune checkpoint blockade therapy. Cancer Discov. 2018;8(9):1069-1086.

114. Rizvi NA, et al. Cancer immunology. Mutational landscape determines sensitivity to PD-1 blockade in non-small cell lung cancer. Science. 2015;348(6230):124-128.

115. Van Allen EM, et al. Genomic correlates of response to CTLA- 4 blockade in metastatic melanoma. Science. 2015;350(6257):207-211.

116. Le DT, et al. Mismatch repair deficiency predicts response of solid tumors to $\mathrm{PD}-1$ blockade. Science. 2017;357(6349):409-413.

117. Armand P, et al. Nivolumab for relapsed/refractory classic Hodgkin lymphoma after failure of autologous hematopoietic cell transplantation: extended follow-up of the multicohort single-arm phase II CheckMate 205 trial. J Clin Oncol. 2018;36(14):1428-1439.

118. Green MR, et al. Integrative analysis reveals selective 9p24.1 amplification, increased PD-1 ligand expression, and further induction via JAK2 in nodular sclerosing Hodgkin lymphoma and primary mediastinal large B-cell lymphoma. Blood. 2010;116(17):3268-3277.

119. Green MR, et al. Constitutive AP-1 activity and EBV infection induce PD-L1 in Hodgkin lymphomas and posttransplant lymphoproliferative disorders: implications for targeted therapy. Clin Cancer Res. 2012;18(6):1611-1618.

120. Davids MS, et al. Ipilimumab for patients with relapse after allogeneic transplantation. $\mathrm{NEnglJ}$ Med. 2016;375(2):143-153.

121. Garcia-Manero G, et al. A phase II study evaluating the combination of nivolumab (Nivo) or ipilimumab (Ipi) with azacitidine in pts with previously treated or untreated myelodysplastic syndromes (MDS). Blood. 2016;128(22):344.

122. Carreno BM, et al. Cancer immunotherapy. A dendritic cell vaccine increases the breadth and diversity of melanoma neoantigen-specific $\mathrm{T}$ cells. Science. 2015;348(6236):803-808.

123. Brusic A, et al. Detecting T-cell reactivity to whole cell vaccines: proof of concept analysis of T-cell response to K562 cell antigens in CML patients. Oncoimmunology. 2012;1(7):1095-1103.

124. Rosenblatt J, et al. Individualized vaccination of AML patients in remission is associated with induction of antileukemia immunity and prolonged remissions. Sci Transl Med. 2016;8(368):368ra171.

125. Sahin U, et al. Personalized RNA mutanome vaccines mobilize poly-specific therapeutic immunity against cancer. Nature. 2017;547(7662):222-226.

126. Hu Z, Ott PA, Wu CJ. Towards personalized, tumour-specific, therapeutic vaccines for cancer Nat Rev Immunol. 2018;18(3):168-182.

127. Li L, Goedegebuure SP, Gillanders WE. Preclinical and clinical development of neoantigen vaccines. Ann Oncol. 2017;28(suppl 12):xii11-xii17.

128. Johanns TM, et al. Detection of neoantigenspecific $\mathrm{T}$ cells following a personalized vaccine in a patient with glioblastoma. Oncoimmunology. 2019;8(4):e1561106.

129. Sonntag K, et al. Immune monitoring and TCR sequencing of CD4 $\mathrm{T}$ cells in a long term responsive patient with metastasized pancreatic ductal carcinoma treated with individualized, neoepitope-derived multipeptide vaccines: a case report. J Transl Med. 2018;16(1):23.

130. Maude SL, et al. Chimeric antigen receptor T cells for sustained remissions in leukemia. N Engl JMed. 2014;371(16):1507-1517.

131. Raje N, et al. Anti-BCMA CAR T-cell therapy bb2121 in relapsed or refractory multiple myeloma. N Engl J Med. 2019;380(18):1726-1737.

132. Cohen $\mathrm{AD}$, et al. B cell maturation antigenspecific CAR T cells are clinically active in multiple myeloma. JClin Invest. 2019;129(6):2210-2221.

133. Ghorashian S, et al. Enhanced CAR T cell expansion and prolonged persistence in pediatric patients with ALL treated with a low-affinity CD19 CAR. Nat Med. 2019;25(9):1408-1414

134. Chapuis AG, et al. Transferred WT1-reactive $\mathrm{CD}^{+} \mathrm{T}$ cells can mediate antileukemic activity and persist in post-transplant patients. Sci Transl Med. 2013;5(174):174ra27.

135. Chapuis AG, et al. T cell receptor gene therapy targeting WT1 prevents acute myeloid leukemia relapse post-transplant. Nat Med. 2019;25(7):1064-1072.

136. Rosenberg SA, Restifo NP. Adoptive cell transfer as personalized immunotherapy for human cancer. Science. 2015;348(6230):62-68.

137. Tran E, et al. Cancer immunotherapy based on mutation-specific $\mathrm{CD}^{+}{ }^{+} \mathrm{T}$ cells in a patient with epithelial cancer. Science. 2014;344(6184):641-645.

138. Tran E, et al. T-cell transfer therapy targeting mutant KRAS in cancer. $N$ Engl J Med. 2016;375(23):2255-2262.

139. Lo W, et al. Immunologic recognition of a shared p53 mutated neoantigen in a patient with metastatic colorectal cancer. Cancer Immunol Res. 2019;7(4):534-543.

140. Hutten TJA, et al. Increased coexpression of PD-1, TIGIT, and KLRG-1 on tumor-reactive $\mathrm{CD}^{+} \mathrm{T}$ cells during relapse after allogeneic stem cell transplantation. Biol Blood Marrow Transplant. 2018;24(4):666-677.
141. Christopher MJ, et al. Immune escape of relapsed AML cells after allogeneic transplantation. N Engl J Med. 2018;379(24):2330-2341.

142.Anagnostou V, et al. Evolution of neoantigen landscape during immune checkpoint blockade in non-small cell lung cancer. Cancer Discov. 2017;7(3):264-276.

143. Sade-Feldman M, et al. Resistance to checkpoint blockade therapy through inactivation of antigen presentation. Nat Commun. 2017;8(1):1136.

144. Bachireddy P, et al. Reversal of in situ T-cell exhaustion during effective human antileukemia responses to donor lymphocyte infusion. Blood. 2014;123(9):1412-1421.

145. Davids MS, et al. A phase I/Ib study of nivolumab for relapsed hematologic malignancies after allogeneic hematopoietic cell transplantation (alloHCT). Blood. 2018;132(1 suppl):705.

146.Ijaz A, et al. Significant risk of graft-versus-host disease with exposure to checkpoint inhibitors before and after allogeneic transplantation. Biol Blood Marrow Transplant. 2019;25(1):94-99.

147. Gress RE, et al. Proceedings from the National Cancer Institute's Second International Workshop on the Biology, Prevention, and Treatment of Relapse after Hematopoietic Stem Cell Transplantation: Part I. Biology of relapse after transplantation. Biol Blood Marrow Transplant. 2013;19(11):1537-1545.

148. Burkhardt UE, et al. Autologous CLL cell vaccination early after transplant induces leukemia-specific T cells. J Clin Invest. 2013;123(9):3756-3765.

149. Ho VT, et al. Biologic activity of irradiated, autologous, GM-CSF-secreting leukemia cell vaccines early after allogeneic stem cell transplantation. Proc Natl Acad Sci U S A. 2009;106(37):15825-15830.

150. Foglietta M, et al. Neoantigen and tumor antigen-specific immunity transferred from immunized donors is detectable early after allogeneic transplantation in myeloma patients. Bone Marrow Transplant. 2013;48(2):269-277.

151. Rosenblatt J, et al. PD-1 blockade by CT-011, antiPD-1 antibody, enhances ex vivo T-cell responses to autologous dendritic cell/myeloma fusion vaccine. JImmunother. 2011;34(5):409-418.

152. Ott PA, et al. A personal neoantigen vaccine, NEO-PV-01, with anti-PD1 induces broad de novo anti-tumor immunity in patients with metastatic melanoma, NSCLC, and bladder cancer. Ann Oncol. 2018;29(8 suppl): viii400-viii441.

153. Finney OC, et al. CD19 CAR T cell product and disease attributes predict leukemia remission durability. J Clin Invest. 2019;129(5):2123-2132.

154.Akahori Y, et al. Antitumor activity of CAR-T cells targeting the intracellular oncoprotein WT1 can be enhanced by vaccination. Blood . 2018;132(11):1134-1145.

155. Chong EA, et al. PD-1 blockade modulates chimeric antigen receptor (CAR)-modified T cells: refueling the CAR. Blood. 2017;129(8):1039-1041.

156. Chong EA, et al. Phase I/II study of pembrolizumab for progressive diffuse large B cell lymphoma after anti-CD19 directed chimeric antigen receptor modified T cell therapy. Blood. 2017;130(suppl 1):4121.

157. Maude SL, et al. The effect of pembrolizumab in combination with CD19-targeted chimeric antigen receptor (CAR) $\mathrm{T}$ cells in relapsed acute 
lymphoblastic leukemia (ALL). JClin Oncol. 2017;35(15 suppl):103.

158. Powell DJ, Dudley ME, Hogan KA, Wunderlich JR, Rosenberg SA. Adoptive transfer of vaccineinduced peripheral blood mononuclear cells to patients with metastatic melanoma following lymphodepletion. JImmunol. 2006;177(9):6527-6539.

159. Wickström SL, et al. Abstract CT032: Adoptive $\mathrm{T}$ cell transfer combined with $\mathrm{DC}$ vaccination in patients with metastatic melanoma. Cancer Res. 2018;78(13 suppl):CT032.

160.Penter $\mathrm{L}$, et al. Localization-associated immune phenotypes of clonally expanded tumor-infiltrating $\mathrm{T}$ cells and distribution of their target antigens in rectal cancer. Oncoimmunology. 2019;8(6):e1586409.

161. Scheper W, et al. Low and variable tumor reactivity of the intratumoral TCR repertoire in human cancers. Nat Med. 2019;25(1):89-94.

162. Simoni $\mathrm{Y}$, et al. Bystander $\mathrm{CD} 8^{+} \mathrm{T}$ cells are abundant and phenotypically distinct in human tumour infiltrates. Nature. 2018;557(7706):575-579.

163. Philip M, et al. Chromatin states define tumour-specific $\mathrm{T}$ cell dysfunction and reprogramming. Nature. 2017;545(7655):452-456.

164. Gee MH, et al. Antigen identification for orphan $\mathrm{T}$ cell receptors expressed on tumor-infiltrating lymphocytes. Cell. 2018;172(3):549-563.e16.

165. Gros A, et al. Prospective identification of neoantigen-specific lymphocytes in the peripheral blood of melanoma patients. Nat Med. 2016;22(4):433-438.

166. Lu YC, et al. An efficient single-cell RNA-seq approach to identify neoantigen-specific $\mathrm{T}$ cell receptors. Mol Ther. 2018;26(2):379-389.
167. Han A, Glanville J, Hansmann L, Davis MM. Linking T-cell receptor sequence to functional phenotype at the single-cell level. Nat Biotechnol. 2014;32(7):684-692.

168. Li S, et al. RNase H-dependent PCR-enabled $\mathrm{T}$-cell receptor sequencing for highly specific and efficient targeted sequencing of T-cell receptor mRNA for single-cell and repertoire analysis. Nat Protoc. 2019;14(8):2571-2594.

169.Hansmann L, Han A, Penter L, Liedtke M, Davis MM. Clonal expansion and interrelatedness of distinct B-lineage compartments in multiple myeloma bone marrow. Cancer Immunol Res. 2017;5(9):744-754.

170.Penter L, Dietze K, Bullinger L, Westermann J, Rahn HP, Hansmann L. FACS single cell index sorting is highly reliable and determines immune phenotypes of clonally expanded T cells. Eur J Immunol. 2018;48(7):1248-1250.

171. Bengsch B, et al. Epigenomic-guided mass cytometry profiling reveals disease-specific features of exhausted CD8 T cells. Immunity. 2018;48(5):1029-1045.e5.

172. Purroy N, Wu CJ. Coevolution of leukemia and host immune cells in chronic lymphocytic leukemia. Cold Spring Harb Perspect Med. 2017;7(4):a026740.

173. Eyquem J, et al. Targeting a CAR to the TRAC locus with CRISPR/Cas9 enhances tumour rejection. Nature. 2017;543(7643):113-117.

174. Kula T, et al. T-Scan: a genome-wide method for the systematic discovery of $\mathrm{T}$ cell epitopes. Cell. 2019;178(4):1016-1028.e13.

175. Goltsev Y, et al. Deep profiling of mouse splenic architecture with CODEX multiplexed imaging.
Cell. 2018;174(4):968-981.e15.

176. Bleakley M, et al. Leukemia-associated minor histocompatibility antigen discovery using $\mathrm{T}$-cell clones isolated by in vitro stimulation of naive CD8 ${ }^{+}$T cells. Blood. 2010;115(23):4923-4933.

177. Van Bergen CA, et al. High-throughput characterization of 10 new minor histocompatibility antigens by whole genome association scanning. Cancer Res. 2010;70(22):9073-9083.

178. Pont MJ, et al. LB-ARHGDIB-1R as a novel minor histocompatibility antigen for therapeutic application. Haematologica. 2015;100(10):e419-e422.

179. Pont MJ, et al. Integrated whole genome and transcriptome analysis identified a therapeutic minor histocompatibility antigen in a splice variant of ITGB2. Clin Cancer Res. 2016;22(16):4185-4196.

180. Kawase T, et al. Alternative splicing due to an intronic SNP in HMSD generates a novel minor histocompatibility antigen. Blood. 2007;110(3):1055-1063.

181. Oostvogels R, et al. Towards effective and safe immunotherapy after allogeneic stem cell transplantation: identification of hematopoieticspecific minor histocompatibility antigen UTA21. Leukemia. 2013;27(3):642-649.

182.de Rijke B, et al. A frameshift polymorphism in P2X5 elicits an allogeneic cytotoxic T lymphocyte response associated with remission of chronic myeloid leukemia. JClin Invest. 2005;115(12):3506-3516.

183. Griffioen M, van Bergen CA, Falkenburg JH. Autosomal minor histocompatibility antigens: how genetic variants create diversity in immune targets. Front Immunol. 2016;7:100. 